\title{
Help-Seeking Behaviors of Men for Mental Health and the Impact of Diverse Cultural Backgrounds
}

\author{
Sylvia Lindinger-Sternart ${ }^{1}$ \\ ${ }^{1}$ College of Education, the Pennsylvania State University, State College, United States. \\ Correspondence: Sylvia Lindinger-Sternart, College of Education, Department of Educational Psychology, Counseling, \\ and Special Education, The Pennsylvania State University, State College, PA, United States.
}

Received: September 21, 2014

Accepted: October 16, $2014 \quad$ Available online: October 20, 2014

doi:10.11114/ijsss.v3i1.519

URL: http://dx.doi.org/10.11114/ijsss.v3i1.519

\begin{abstract}
A growing research body suggests that men are less likely than women to seek help from professional counselors for mental health problems and stressful life events (Komiya, Good, \& Sherrod, 2000). Untreated mental health problems can have a significant impact on the health and development of the client as well as the client's family members. Various factors such as help-seeking attitudes influence men's help-seeking behaviors in regard to mental health services. Males demonstrate less positive attitudes toward seeking help in order to avoid talking about stressful events and painful feelings because of masculine norms and stigma. Help-seeking attitudes, masculine norms, and stigma are reviewed for their associations with men's opposition to seeking help when psychological problems occur. The author of this paper presents further literature about males from diverse cultural backgrounds to emphasize the particular factors that impact men's reduced willingness to seek counseling.
\end{abstract}

Keywords: help-seeking attitude, seeking help, masculinity, masculine norms, stigma

\section{Men's Help-Seeking Behaviors and Attitudes Regarding Mental Health Services}

The World Health Organization (WHO, 2010) stated mental health is an integral and significant element of health. Importantly, mental health is defined as more than the absence of mental health disorders. Determinants of mental health are biological, psychological, and social factors that play a significant role for a person at any point of time (WHO, 2010). Mental health disorders impact individuals of all cultures and ages around the world. Statistical estimates show that $26 \%$ of Americans ages 18 and older have a diagnosable mental health disorder in a given year. Mental disorders are the leading cause of disability in the United States and are related to comorbidity with substance abuse disorder, or suicide. The highest suicide rates are found in males (NIMH National Institute of Mental Health, 2013). Looking at these facts, seeking help from a professional counselor can enhance men's mental health and prevent many negative consequences. However, males are less likely to seek counseling when they face psychological problems (Komiya, Good, \& Sherrod, 2000).

The highest suicide rates are found in males (NIMH National Institute of Mental Health, 2013). Looking at these facts, seeking help from a professional counselor can enhance men's mental health and prevent many negative consequences. However, males are less likely to seek counseling when they face psychological problems (Komiya, Good, \& Sherrod, 2000).

\section{Help-Seeking Attitudes}

Help-seeking attitudes predict health-related behaviors such as seeing a counselor (Armitage \& Conner, 2001). Gender is a significant variable related to attitudes toward seeking counseling for mental health issues. A national epidemiological sample showed that young men have the most negative attitudes toward mental health treatment (Gondalez, Alegria, \& Prihoda, 2005). Males demonstrate reduced help-seeking attitudes' in order to avoid talking about distressing events (Vogel \& Wester, 2003), to avoid feeling painful emotions (Komiya et al., 2000), and to prevent social stigma (Deane \& Chamberlain, 1994). Similarly, Vogel, Wester, Wei, and Boysen (2005) found that social stigma, social norm, emotional self-disclosure, previous use of counseling and expected outcomes predicted men's help-seeking attitudes. Prior counseling experience and outcome expectations were particularly important to clients who have experienced a stressful event. Once a man had pursued counseling, bond and perceptions of counseling helpfulness were more important for his future help-seeking attitude than restricted emotionality (Cusack, Deane, Wilson, \& 
Ciarrochi, 2006a). Gender role conflicted men restrict their emotionality to avoid being perceived as feminine. Thus, they may have more difficulties disclosing or accepting strong emotions in the counseling process (Kierski \& Blazina, 2009).

Men with less positive attitude toward help-seeking has been found constant over time and cultures (Nam et al., 2010a) and may be influenced by the level of conformity to masculine norms and a greater self-stigmatizing perception. Men who relate to more dominant gender roles, which are based on masculinity and self-support, have self-stigmatizing perceptions that lead toward less positive attitudes toward counseling (Vogel et al., 2011). Williams and Justice (2010) found that African American students' concerns regarding seeking counseling were negative stigmas, signs of weakness, and fear of embarrassment. Masculine cultures such as the United States or Japan show stronger gender differences in help-seeking attitudes compared to feminine cultures such as Sweden or France (Nam et al., 2010a).

\section{Masculine Norms}

Traditional masculine gender norms are linked to reduced help-seeking behavior in men. Most cultural masculine norms are: appearing strong, not emotional, and independent. These norms not associated with vulnerability and weakness, such as help seeking which is avoided (Pederson \& Vogel, 2007).

In the United States, conventional masculine norms are specified by the dominant culture and affirm that males should be stoic, dominant, emotionally controlled, and self-sufficient, and conformity to these norms has been related to reduce help-seeking behavior (Mahalik et al., 2003). Theorists have postulated that men are socialized to hide their emotions and to handle their problems on their own, which leads to higher rates of psychopathology (Cochran \& Rabinowitz, 2000). The masculinity of men from diverse racial backgrounds is related to physical stereotypes such as height or athletic abilities. Wong, Horn, and Chen (2013) found huge differences in perceived masculinity between Asian American and Black/White American men. More research is needed to investigate masculinity variables in various ethical groups.

\subsection{Stigma}

Stigma plays a significant role in men's help-seeking behavior. Self-stigma accounted for 56\% of the variance in men's help-seeking attitudes and mediated the relationship between masculine norms and help-seeking attitudes across various ethnic groups (Vogel et al., 2011). Men showed elevated levels of stigma toward help-seeking and reluctance to see a counselor (Galdas, Cheater, \& Marshall, 2005). Brown et al. (2010) found a correlation between internalized stigma and help-seeking attitudes toward mental health in Caucasians and African Americans. However, a direct effect of internalized stigma on help-seeking behavior was found only in African American males.

Military and sport may influence males' perception of stigma when seeking help for mental health problems. Men within sports who showed high levels of conformity to masculine norms had significantly higher levels of stigma toward help-seeking (Steinfeld \& Steinfeldt, 2012). Psychological self-assurance predicted promotions in the U.S. Military Academy over four years (Bartone, Eid, Johnson, Laberg, \& Snook, 2009) as well predicted successful completion of a training program for U.S. Army Special Forces (Bartone, Roland, Picano, \& Williams, 2008). Police officers' conflict between the norms of gender and their personal role as a man was associated with stigma toward counseling (Wester, Arndt, Sedivy, \& Arndt, 2010).

\section{Diverse Cultural Backgrounds}

\subsection{Caucasians}

Fear of being seen as "not a real man" may be an organizing principle of dominant cultural definitions of masculinity (Robinson, 2008). Counselors who work with men should assess the conformity to specific norms and the possible association to presenting problems in counseling. The Conformity to Masculine Norms Inventory (CMNI) was developed to assess the extent to which a male conforms to major masculinity norms found in the dominant culture in the United States. The norms are: winning, emotional control, risk-taking, violence, dominance, playboy image, self-reliance, primacy of work, power over women, disdain for homosexuality, and pursuit of status (Mahalik \& Talmadge, 2005). Men with higher levels of education represented lower scores of conformity to masculine norms (Reilly, Rochlen, \& Awad, 2013).

It is important for counselors to be aware of masculine cultural values in a multicultural environment. Men are socialized in particular cultures, with values, norms, traditions, and expectations to which they have to conform. To give an example, Swedish modern masculinity is considered less authoritarian, less violent, more emotional, and more gender equality oriented than other and earlier masculinities (Hearn, et al., 2012).

\subsection{African Americans}

Cultural distrust and experiences with racism may increase African-American men's negative attitude toward 
counseling (Hammond, 2012). African-American men may present themselves as unbothered and stoic in public but show a different face in their homes. Restrictive emotionality and self-reliance was associated with increased suicide rates in African American men. However, younger African American males showed higher masculine role norm conformity and restrictive emotionality than aged men 40 years or older (Hammond, 2012). In contrast, Vogel et al. (2011) suggested that African American men have more expressive communication styles compared to other men and may feel more comfortable when disclosing information to a counselor.

\subsection{Asian Americans}

Asian men's traditional gender role expectations include emotional restraint, which may have a limiting effect on seeking counseling and sharing personal information (Lui \& Iwamoto, 2006). The Asian American masculinity concept is mainly externally defined and may have created negative self-evaluations due to a failure to meet the dominant culture's expectations. In addition, Asian cultural values such as humility and collectivism are in contrast to masculine norms in the United States and are described as feminine (Chan, 2001).

Conformity to these cultural expectations may impact Asian American men's attitude toward help-seeking negatively. Asian Americans represent lower rates of help-seeking compared to any other racial or ethnic group (Lui et al., 2006). $\mathrm{Chu}$, Hsieh, and Tokars (2011) found that language proficiency was a significantly related predictor of help-seeking behavior among Asian Americans but not Latinos. Asian Americans students preferred more privacy in counseling. Importantly, 35\% of Asian American males with suicide attempts have never sought any help from counselors'. Rather they contacted nonprofessional sources such as online support groups, self-help groups, and hotlines. Educational efforts are required to reach Asian Americans for mental health provisions (Ruzek, Nguyen, \& Herzog, 2011).

\subsection{Latinos}

The population of Latino men is growing in the United States and Latino masculinity has been built and rebuilt within the dominant culture. In Latinos language proficiency and immigration age were not significantly related to help-seeking behavior compared to Asian Americans (Chu et al., 2011). One common racial stereotype of Latino males is they are aggressive, hyper-sexualized, and disposed to use alcohol and to abuse women. Usually, these stereotypes of Latino men are described with the term machismo. Machismo is used to explain Latino men and their masculinity (Arciniega, Anderson, Tovar-Blank, \& Tracey, 2008). Research implied that some Latino males may believe to follow such machismo principles (Torres, Solberg, \& Carlstrom, 2002). Machismo beliefs of Latino men were related to negative mental health. For instance, Latino masculinity was related to restrictive emotionality and depression in males (Fragoso \& Kashubeck, 2000). Although men from other cultures show the same behaviors, machismo has become a term to describe Latino masculinity and includes racism. Arciniega et al. (2008) emphasize that the masculine roles of Latino men include also positive characteristics such as honor, respect, dignity, and value for the family. Therefore, Latino masculine identity involves both traditional machismo and positive features, called caballerismo. Men of color experience racism more often, and that increases their conflict between the role of bread winner and the cultural masculine expectations (O’Neil, 2008). However, Liang, Salcedo, and Miller (2011) found a correlation between high levels of machismo dogma and high levels of restrictive emotionality in Latino men with low and high levels of racism.

\subsection{Native Americans}

Few researchers have investigated help-seeking attitudes of Native American males. Bee-Gates, Howard-Pitney, LaFromboise, and Row (1996) examined Native American high school students in an empirical study, and results showed the participants were seeking help mostly from their families for personal problems and used professional help primarily for career and academic challenges. Native Americans who face problems with alcohol use disorders were experiencing barriers such as quality of care when seeking counseling (Venner et al., 2012). Problems with communication and trust and expectations of discrimination were preventing Native Americans from seeking help (Duran et al., 2005). Some Native Americans reported that prejudice from government and officials were barriers to seeking counseling for mental health problems (Jones-Saumty, Thomas, Phillips, Tivis, \& Nixon, 2003). In addition, Native Americans described absence of cultural considerations such as traditional healing modalities as barriers to seeking counseling (Herman-Stahl, Spencer, \& Duncan, 2003). Self-help group settings without other Native Americans present have been documented as uncomfortable for some Native Americans (Venner et al., 2012) and some were afraid of prejudice and discrimination (Duran et al., 2005). To conclude, fear of discrimination seems to be a crucial factor in Native Americans avoidance of seeking professional counseling.

\section{Conclusion and Implication for Mental Health Professions}

The counseling profession may want to consider addressing attitudes toward help-seeking, healthy masculine norms, and stigma to encourage men from diverse cultural backgrounds to pursue counseling services. Toughness and self-sufficiency combined with shame and shyness may affect men's help-seeking attitude negatively and cause them to 
postpone help-seeking behavior for treatment (Pearson \& Madadzange, 2008). A qualitative study by Timlin-Scalera, Ponterotto, Blumberg, and Jackson (2003) showed that European American males who were living in a traditional, conservative, and prosperous community experienced enormous pressure to fit in and to maintain their strong and independent image, which minimized their help-seeking attitudes.

Professional counselors view their clients as experts of their lives and empower them to achieve their individual goals. Assisting men to realize that counselors want to help them to unearth their strengths may increase their willingness to seek help. Theories that build on the strengths and resources that the individual already has may attract men. For example, positive psychology could suit men well and increase their expectations of positive outcomes. Venner et al. (2012) states motivational interviewing is a good method to address men's concerns about self-reliance and autonomy.

Gender role conflicts and stigma are important issues when working with male clients from various cultural backgrounds. Clients' view of masculinity and their desire to confirm to masculine norms can be linked to their problems. Specifically, men who are engaged in sports or work in the military or police may identify themselves to a higher level with these norms of masculinity and toughness and may not recognize the benefits of seeking counseling (Steinfeld \& Steinfeld, 2012). All in all, professional counselors should actively promote their services by emphasizing that counseling maximizes clients' strengths and success in life, sport, and work.

\section{References}

Armitage, C., \& Conner, M. (2001). Efficacy of theory of planned behaviour: A meta-analytic review. British Journal of Social Psychology, 40, 471-499.

Arciniega, G. M., Anderson, T. C., Tovar-Blank, Z., \& Tracey, T. J. G. (2008). Toward a fuller conception of machismo: Development of a traditional machismo and caballerismo scale. Journal of Counseling Psychology, 55, 19-33. http://dx.doi.org/10.1037/0022-0167.55.1.19

Bartone, P. T., Eid, J., Johnsen, B. H., Laberg, J. C., \& Snook, S. A. (2009). Big five personality factors, hardiness, and social judgment as predictors of leader performance. Leadership \& Organization Development Journal, 30, 498-521. http://dx.doi.org/10.1108/01437730910981908

Bartone, P. T., Roland, R. R., Picano, J. J., \& Williams, T. J. (2008). Psychological hardiness predicts success in US army special forces candidates. International Journal of Selection \& Assessment, 16, 78-81. http://dx.doi.org/10.1111/j.1468-2389.2008.00412.x

Bee-Gates, D., Howard-Pitney, B., LaFromboise, T., \& Rowe, W. (1996). Help-seeking behavior of Native American Indian high school students. Professional Psychology: Research and Practice, 27, 495-499. http://dx.doi.org/10.1037/0735-7028.27.5.495

Brown, C., Conner, K. O., Copeland, V. C., Grote, N., Beach, S., Battista, D., \& Reynolds III, C. F. (2010). Depression stigma, race, and treatment seeking behavior and attitudes. Journal of Community Psychology, 38, 350-368.

Chan, J. (2001). Chinese American masculinities: From Fu Manchu to Bruce Lee. New York: Routledge.

Chu, J. P., Hsieh, K-Y., \& Tokars, D. A. (2011). Help-seeking tendencies in Asian Americans with suicidal ideation and attempts. Asian American Journal of Psychology, 2, 26-38. http://dx.doi.org/10.1037/a0023326.

Cochrank, S. V., \& Rabinowitz, F. E. (2000). Men and depression: Clinical and empirical perspectives: Practical resources for the mental health professional. San Diego, CA: Academic Press.

Cusack, J., Deane, F. P., Wilson, C. J., \& Ciarrochi, J. (2006). Emotional expression, perceptions of therapy, and help-seeking intentions in men attending therapy services. Psychology of Men \& Masculinity, 7, 69-82. http://dx.doi.org/10.1037/1524-9220.7.2.69

Deane, F. P., \& Chamberlain, K. (1994). Treatment fearfulness and distress as predictors of professional psychological help-seeking. British Journal of Guidance \& Counselling, 22, 207-217.

Duran, B., Oetzel, J., Lucero, J., Jiang, Y., Novins, D. K., Manson, S., \& Beals, J. (2005). Obstacles for rural American Indians seeking alcohol, drug, or mental health treatment. Journal of Consulting and Clinical Psychology, 73, 819-829. http://dx.doi.org/10.1037/0022-006X.73.5.819

Fragoso, J. M., \& Kashubeck, S. (2000). Machismo, gender role conflict, and mental health in Mexican American men. Psychology of Men \& Masculinity, 1, 87-97. http://dx.doi.org/10.1037/1524-9220.1.2.87

Galdas, P. M., Cheater, F., \& Marshall, P. (2005). Men and health help-seeking behaviour: Literature review. Journal of Advanced Nursing, 49, 616-622. http://dx.doi.org/10.1111/j.1365-2648.2004.03331.x

Gonzalez, J. M., Alegria, M., \& Prihoda, T. J. (2005). How do attitudes toward mental health treatment vary by age, 
gender, and ethnicity/race in young adults? Journal of Community Psychology, 5, 611-629. http://dx.doi.org/10.1002/jcop.20071

Hammond, W. P. (2012). Taking it like a man: Masculine role norms as moderators of the racial discrimination-depressive symptoms association among African American men. American Journal of Public Health, 102, S232-S241. http://dx.doi.org/10.2105/AJPH.2011.300485

Hearn, J., Nordberg, M., Andersson, K., Balkmar, D., Gottzén, L., Klinth, R., . . . Sandberg, L. (2012). Hegemonic masculinity and beyond: 40 years of research in Sweden. Men and Masculinities, 1, 31-55. http://dx.doi.org/10.1177/1097184X11432113

Herman-Stahl, M., Spencer, D. L., \& Duncan, J. E. (2003). The implications of cultural orientation for substance use among American Indians. American Indian \& Alaska Native Mental Health Research: The Journal of the National Center, 11, 46-66.

Jones-Saumty, D., Thomas, B., Phillips, M. E., Tivis, R. and Nixon, S. J. (2003), Alcohol and health disparities in non-reservation American Indian communities. Alcoholism: Clinical and Experimental Research, 27, 1333-1336. http://dx.doi.org/10.1097/01.ALC.0000080343.90121.25

Kierski, W., \& Blazina, C. (2009). The male fear of the feminine and its effects on counseling and sychotherapy Journal of Men's Studies, 17, 155-172.

Komiya, N., Good, G. E., \& Sherrod, N. B. (2000). Emotional openness as a predictor of college students' attitudes toward seeking psychological help. Journal of Counseling Psychology, 47, 138-143. http://dx.doi.org/10.1037/0022-0167.47.1.138

Liang, C. T. H., Salcedo, J., \& Miller, H. A. (2011). Perceived racism, masculinity ideologies, and gender role conflict among Latino men. Psychology of Men \& Masculinity, 12, 201-215. http://dx.doi.org/10.1037/a0020479

Liu, W. M., \& Iwamoto, D. K. (2006). Asian American men's gender role conflict. The role of Asian values, self-esteem, and psychological distress. Psychology of Men and Masculinity, 7, 153-164. http://dx.doi.org/10.1037/1524-9220.7.3.153

Mahalik, J. R., Locke, B. D., Ludlow, L. H., Deimer, M. A., Scott, R. P. J., Gottfried, M., \& Freitas, G. (2003). Development of the conformity to masculine norms inventory. Psychology of Men and Masculinity, 4, 3-25. http://dx.doi.org/10.1037/1524-9220.3.1.3

Mahalik, J. R., Talmadge, W. T., Locke, B. D., \& Scott, R. P. J. (2005). Using the conformity to masculine norms inventory to work with men in a clinical setting. Journal of Clinical Psychology, 6, 661-674. http://dx.doi.org/10.1002/jclp.20101

Nam, S. K., Chu, H. J., Lee, M. K., Lee, J. H., Kim, N., \& Lee, S. M. (2010). A meta-analysis of gender differences in attitudes toward seeking professional psychological help. Journal of American College Health, 59, 110-116.

NIMH National Institute of Mental Health. (2013). Transforming the understanding and treatment of mental illness through research.

http://www.nimh.nih.gov/health/publications/the-numbers-count-mental-disorders-in-america/index.shtml.

O'Neil, J. M. (2008). Summarizing 25 years of research on men's gender role conflict using the gender role conflict scale: New research paradigms and clinical implications. The Counseling Psychologist, 36, 358-445. http://dx.doi.org/10.1177/0011000008317057

Pearson, S., \& Makadzange, P. (2008). Help-seeking behaviour for sexual-health concerns: A qualitative study of men in Zimbabwe. Culture, Health \& Sexuality, 10, 361-376. http://dx.doi.org/10.1080/13691050801894819

Pederson, E. L., \& Vogel, D. L. (2007). Male gender role conflict and willingness to seek counseling: Testing a

mediation model on college-aged men. Journal of Counseling Psychology, 54, 373-384. http://dx.doi.org/10.1037/0022-0167.54.4.373

Reilly, E. D., Rochlen, A. B., \& Awad, G. H. (2013). Men's self-compassion and self-esteem: The moderating roles of shame and masculine norm adherence. Psychology of Men \& Masculinity, No Pagination Specified. http://dx.doi.org/10.1037/a0031028

Robinson, V. (2008). Men, masculinities and feminism in D. Richardson and V. Robinson (Eds.). Introducing Gender and Women's Studies, $3^{\text {rd }}$ Edition. Basingstoke: Palgrave Macmillan. 
Ruzek, N. A., Nguyen, D. Q., \& Herzog, D. C. (2011). Acculturation, enculturation, psychological distress and help-seeking preferences among Asian American college students. Asian American Journal of Psychology, 2, 181-196. http://dx.doi.org/10.1037/a0024302

Soorkia, R., Snelgar, R., \& Swami, V. (2011). Factors influencing attitudes towards seeking professional psychological help among South Asian students in Britain. Mental Health, Religion \& Culture, 14, 613-623. http://dx.doi.org/10.1080/13674676.2010.494176

Steinfeldt, J. A., \& Steinfeldt, M. C. (2012). Profile of masculine norms and help-seeking stigma in college football. Sport, Exercise, and Performance Psychology, 1, 58-71. http://dx.doi.org/10.1037/a0024919

Timlin-Scalera, R., Ponterotto, J. G., Blumberg, F. C., \& Jackson, M. A. (2003). A grounded theory study of help-seeking behaviors among white male high school students. Journal of Counseling Psychology, 50, 339-350. http://dx.doi.org/10.1037/0022-0167.50.3.339

Torres, J. B., Solberg, V. S., \& Carlstrom, A. H. (2002). The myth of sameness among Latino men and their machismo. American Journal of Orthopsychiatry, 72, 163-181. http://dx.doi.org/10.1037/0002-9432.72.2.163

Venner, K. L., Greenfield, B. L., Vicuña, B., Muñoz, R., Bhatt, S., \& O'Keefe, V. (2012). "I'm not one of them": Barriers to help-seeking among American Indians with alcohol dependence. Cultural Diversity and Ethnic Minority Psychology, 18, 352-362. http://dx.doi.org/10.1037/a0029757

Vogel, D. L., Heimerdinger-Edwards, S., Hammer, J. H., \& Hubbard, A. (2011). "Boys don't cry". Journal of Counseling Psychology, 58, 368-382. http://dx.doi.org/10.1037/a0023688

Vogel, D. L., \& Wester, S. R. (2003). To seek help or not to seek help: The risks of self-disclosure. Journal of Counseling Psychology, 50, 351-361. http://dx.doi.org/10.1037/0022-0167.50.3.351

Vogel, D. L., Wester, S. R., Wei, M., \& Boysen, G. A. (2005). The role of outcome expectations and attitudes on decisions to seek professional help. Journal of Counseling Psychology, 52, 459-470. http://dx.doi.org/10.1037/0022-0167.52.4.459

Wester, S. R., Arndt, D., Sedivy, S. K., \& Arndt, L. (2010). Male police officers and stigma associated with counseling: The role of anticipated risks, anticipated benefits and gender role conflict. Psychology of Men \& Masculinity, 11, 286-302. http://dx.doi.org/10.1037/a0019108

Williams, A., \& Justice, M. (2010). Attitudes of African American males regarding counseling in four Texas universities. Education, 131, 158-168.

Wong, Y. J., Horn, A., \& Chen, S. (2013). Perceived masculinity: The potential influence of race, racial essentialist beliefs, and stereoypes. Psychology of Men \& Masculinity, 1, 1-13. http://dx.doi.org/10.1037/z0030100.

World Health Organization. (2010). Mental health: Strengthening our response. http://www.who.int/mediacentre/factsheets/fs220/en/_.Retrieved February 21, 2013.

\section{(cc) $\mathrm{EY}$}

This work is licensed under a Creative Commons Attribution 3.0 License. 